\title{
EDUCAÇÃO FÍSICA ESCOLAR: TENHO CÂNCER E BAIXA VISÃO, POSSO PARTICIPAR?
}

\author{
SCHOOL PHYSICAL EDUCATION: I HAVE CANCER AND LOW VISION, CAN I PARTICIPATE?
}

EDUCACIÓN FÍSICA ESCOLAR: TENGO CÁNCER Y VISIÓN LIMITADA, PUEDO PARTICIPAR?

\author{
CASCÃO, Isabela Lemos de Lima1 \\ COVIC, Amália Neide 2
}

\section{RESUMO}

Este estudo buscou compreender como as aulas de Educação Física (EF) podem auxiliar uma aluna em tratamento oncológico e de baixa visão a ressignificar seu lugar dentro da cultura escolar. Sob o método da pesquisa-ação, envolve além da aluna, sua médica, sua professora de EF e a coordenadora pedagógica da escola. Concluiu-se que a ressignificação do lugar ocupado pelo aluno paciente oncológico de baixa visão se dá pela: formação autônoma do aluno, construção de um ambiente de aprendizagem da docência, reflexão sobre as questões do cotidiano escolar e as implicações no currículo.

Palavras-chave: Educação de Grupos Atípicos. Retorno Escolar. Educação. Classe Hospitalar. Deficiente Visual.

\section{ABSTRACT}

This study aimed to understand how Physical Education (PE) classes could help a low-vision student under oncologic treatment to find a new significance to her place inside the school culture that she is in. Under the action-research method it involves besides the student, her PE teacher, the school's pedagogical coordinator. It is concluded that the new significance of the place occupied by the low-vision oncology student is given by the autonomous formation of the student; constructing an environment where all participants learn; the understanding of the disease and its implications on the construction of the school curriculum.

Keywords: Atypical Groups Education. School Return. Education. Hospitalar School. Visually Impaired.

\section{RESUMEN}

Este estudio buscó comprender cómo las clases de Educación Física (EF) pueden auxiliar a una alumna en tratamiento oncológico y visión mínima a resignificar su lugar en la cultura escolar. Bajo el método Investigación-acción que involucra a la alumna, a su médica responsable, su profesora de EF y la coordinadora pedagógica de la Escuela. En conclusión la resignificación del lugar ocupado por el paciente oncológico de baja visión depende de la formación autónoma del alumno, de la construcción de un ambiente de aprendizaje de la docencia, de la reflexión sobre las cuestiones del cotidiano escolar, de las implicaciones en el currículo.

Palabras clave: Educación de Grupos Atípicos. Retorno Escolar. Educación. Clase Hospitalaria. Deficiente Visual.

\footnotetext{
1 Universidade Federal de São Paulo - Unifesp - Brasil- Brasil

2 Instituto de Oncologia Pediátrica/Grupo de Apoio a Criança e Adolescente com Universidade Federal de São Paulo - IOP-

GRAACC/Unifesp - São Paulo- Brasil
} 


\section{INTRODUÇÃO}

Sob a influência dos estudos da cultura, entendemos que os eventos humanos seguem uma lógica diferente dos eventos da natureza. Enquanto nos primeiros o ser humano localiza-se no mundo, interpretando-o e dando sentido a si mesmo pelos sinais vividos, nos segundos há imediatez dos eventos que não necessariamente precisam de interpretação.

Para Geertz (2012) a cultura é um sistema de relações sociais entrelaçado por signos interpretáveis. Para ele os acontecimentos sociais, as instituições e os comportamentos, quando descritos por um pesquisador, devem ser realizados com densidade de forma que possibilitem a interpretação dos mesmos em busca de significados socialmente estabelecidos. Por essa ótica, lecionar para alunos especiais exige do professor atenção ao contexto em que seus alunos estão inseridos, assim como a percepção das relações simbólicas estabelecidas para significar suas ações.

A partir da década de 1980, com o avanço nas pesquisas em Oncologia Pediátrica, o quadro em que a maioria da população infantil ou jovem falecia pôde ser substituído por um novo cenário em que a maior parte dessa população sobrevive à doença e, por conseguinte, temos o crescimento do número de crianças e adolescentes que, mesmo considerados doentes crônicos, frequentam a escola (PETRILLI, 2000; KREMER et al., 2013, p.543). Com isso, um novo grupo de alunos passa a frequentar a escola, o dos cronicamente doentes, que possivelmente, enquanto frequentar a instituição escolar, simultaneamente, frequentará a instituição hospitalar.

No Instituto de Oncologia Pediátrica/ Grupo de Apoio ao Adolescente e à Criança com Câncer/Universidade Federal de São Paulo (IOP/Graacc/Unifesp) as crianças e adolescentes em tratamento de câncer recebem estímulos para dar continuidade à vida escolar enquanto estão no hospital ou mesmo quando a terapêutica não exige internação. Ali existe a Escola Móvel/Aluno Específico (EMAE), setor que desenvolve trabalho voltado ao atendimento escolar hospitalar dos alunos enfermos e também aos que já estão curados, mas que, no entanto, ainda sentem necessidade de apoio educacional.

No Brasil o atendimento escolar hospitalar não tem tradição e vem sendo tratado dentro do contexto da educação inclusiva. Desde de a LDB 9394/96 a Educação Especial, aquela destinada a pessoas com necessidades educacionais especiais, abrange todos os níveis de ensino, mas somente no ano de 2001 a Resolução nº 02 estabeleceu Diretrizes Nacionais para a Educação Especial na Educação Básica, delimitando (até o período da pesquisa) legalmente a atividade educacional hospitalar.

Art. 13. $\S 1^{\circ}$. As classes hospitalares e o atendimento em ambiente domiciliar devem dar continuidade ao processo de desenvolvimento e ao processo de aprendizagem de alunos matriculados em escolas da Educação Básica, contribuindo para seu retorno e reintegração ao grupo escolar, e desenvolver currículo flexibilizado com crianças, jovens e adultos não matriculados no sistema educacional local, facilitando seu posterior acesso à escola regular. (RESOLUÇÃO 02/2001). 
Quando em 2004 houve a criação da Secretaria de Educação Continuada, Alfabetização, Diversidade e Inclusão, a Secretaria de Educação Especial foi extinta e as questões voltadas à educação hospitalar passaram a ser geridas por uma secretaria que abarcava todas as áreas da educação nacional. A consequência de tal mudança é que a temática classe hospitalar deixou de ser tratada em documentos legais como ocorreu no Plano Nacional de Educação (PNE) 2011-2020 e a prática da educação voltada aos alunos cronicamente enfermos, carente de amparo legal, voltou a ser estrangeira na Educação Básica, uma vez que professores em processo de formação tem pouco ou nenhum acesso a tal modalidade de ensino, o que gera pouco ou nenhum reconhecimento daquilo que é realizado fora dos padrões da escola regular.

Quando nos voltamos ao contexto dos alunos do IOP/Graacc/Unifesp destaca-se que tanto a doença quanto os tratamentos de tumores podem acarretar sequelas aos pacientes, que são os chamados efeitos tardios. Estes, podem começar a surgir a partir de perdas sensoriais, como a da visão, mas também merecem destaque as questões psicológicas e sociais que se modificam em função de seu quadro clínico (PEMBERGER et al., 2005). Diante de tais interferências na vida do aluno cronicamente enfermo, seu processo educacional seguirá um curso diferenciado em relação ao dos demais alunos.

A literatura nos informa sobre os problemas que cercam a vida estudantil desses pacientes, e aparentemente, existe um espaço entre a escola e o hospital que é preenchido pelos alunos gravemente enfermos, mas que é vazio de construções que potencializem o seu processo de formação educacional e desenvolvimento individual. Este hiato formado entre as duas instituições acarreta em um fenômeno bastante significativo, isto é, o de que os alunos em tratamento de câncer não se sentem pertencentes por completo à comunidade escolar (COVIC; OLIVEIRA, 2011).

A experiência de ministrar aulas de EF para uma aluna com deficiência visual severa é ponto de partida desse estudo, a realidade vivida por uma das pesquisadoras trouxe para sua atuação profissional o desafio de reelaborar a forma de ensinar. A reunião dos fatores deficiência visual, oncologia pediátrica e EF se deu no encontro das pesquisadoras no IOP/Graacc/Unifesp a partir do curso de mestrado Educação e Saúde na Infância e Adolescência da Universidade Federal de São Paulo - Unifesp, quando uma aluna, Helena, em tratamento de tumor no Sistema Nervoso Central (SNC) e acentuada perda da visão reclamou na EMAE a necessidade de irem até sua escola explicar como ela era, pois seus professores não sabiam o que ela poderia ou não fazer.

Enquanto pesquisadoras, inspiradas pelos estudos da cultura para interpretar as ações escolares, voltamo-nos as práticas educativas nas aulas de EF da escola de Helena para entender porque ela anunciava não ser entendida. Nos inserimos e penetramos com profundidade naquele universo localizado e preciso para, interpretar que formas simbólicas representavam o lugar de Helena naquele contexto.

A história vem nos mostrando que a EF escolar tornou-se muito forte quando tentou unificar a condição dos corpos dentro das escolas, na tentativa de promover o que os intelectuais e políticos acreditavam que seria uma sociedade melhor (VAGO, 2002). Porém, a partir da década de 1980, cresceu a necessidade de inflexões sobre o cotidiano e os sujeitos da prática. Tal processo fez com que as pesquisas reconhecessem a necessidade de envolvimento no e com o cotidiano, implicando na 
sua entrada efetiva na escola, indicando, para alguns, a redução de importância da teorização da educação e, no contraponto, aumentando a visibilidade das práticas pedagógicas.

O olhar dos pesquisadores da EF escolar também buscou enxergar as manifestações de cultura nos corpos dos alunos e dos professores da disciplina. Estudos realizados por Jocimar Daolio (2006, p. 48) apontam que o ser humano é fruto da cultura e que o corpo reflete as especificidades "incorporadas" da sociedade a qual pertence. Assim como Geertz (2012), Daolio (2013) alerta para que o corpo não seja visto apenas como biológico, uma vez que, embora semelhantes nos mais diversos lugares do mundo, os corpos expressam valores, costumes e normas da sociedade nas quais estão inseridos.

De posse desse raciocínio, para realizar este estudo foi necessário entender qual cultura corporal estava incorporada nos alunos da turma de Helena, que estabeleciam como norma uma pequena participação dela nas aulas de EF. E também que símbolos poderiam ser interpretados nesta investida para propor a ressignificação das experiências vividas no cenário instalado. Assim, foi necessário entender o que era a aula de EF para os nativos daquela escola, o que seus corpos manifestavam como regras e valores diante das aulas e por que Helena não conseguia participar efetivamente das práticas da EF escolar.

Se a cultura influenciou e influencia o desenvolvimento do homem, tanto do ponto de vista social, como do ponto de vista biológico, podemos afirmar que o ser humano é fruto da cultura. Nesse sentido, Daolio (2006) discute sobre a dicotomia equivocadamente disseminada na EF de que a natureza é ligada ao corpo do homem, e a cultura é ligada ao processo educacional da disciplina. $\mathrm{O}$ autor (2006, p. 63) indica, como maneira de refletir sobre o assunto, o seguinte ponto:

[...] há um patrimônio inato no homem que precisa de alguns ajustes, a fim de que ele adquira determinadas capacidades que o habilitem a uma vida social. Há uma ordem da natureza e uma ordem da cultura, vindo a segunda se sobrepor à primeira.

Ele ainda destaca que o objetivo da EF escolar não deve fazer uso das práticas da cultura corporal de maneira acrítica, mas contemplar as diferenças que existem dentro de um determinado grupo de alunos, para que seja praticada com autonomia e os alunos identifiquem que é exatamente a diferença que os torna iguais (DAOLIO, 2006).

Em busca de caminhos para auxiliar a aluna reclamante de que as questões biológicas em seu corpo limitavam as questões da cultura de movimento que ela desejava praticar, a pergunta central desta pesquisa foi: Como as atividades na EF, dentro da atual cultura escolar, podem favorecer a ressignificação do lugar ocupado pelo aluno paciente oncológico de baixa visão?

\section{MÉTODO}

A fim de encontrar respostas para a pergunta central desta pesquisa, utilizamos o método da pesquisa ação (PA), opção metodológica de caráter ativo e que nos possibilitou ir ao encontro tanto da saúde como da educação e por ser uma prática em pesquisa utilizada nestas duas vertentes do conhecimento humano (THIOLLENT, 1984). 
A reflexão interpretativa-crítica é um processo de compreensão, considerada na PA como intersubjetiva. É um processo pautado nas interpretações elaboradas por meio de trocas entre os diferentes sujeitos envolvidos em pesquisas escolares quando esses põem à crítica as ações em diferentes processos de busca de consenso (HABERMAS, 2001), tais como reuniões, aulas, encontro em sala de professores e outros da tradição escolar.

Com isso foi possível imergir no contexto da escola pesquisada e trazer à tona o conflito entre o que é e o que poderia ser a solicitação e queixa da aluna e, assim, "desmistificar os bloqueios à transformação ou explorar possíveis ações" (THIOLLENT, 1984, p. 48).

\section{A ESCOLA INVESTIGADA E OS PARTICIPANTES DA PESQUISA}

Localizada na zona leste da cidade de São Paulo, a escola de Helena, é pública e regida pela Secretaria de Educação Municipal (SME). Recente no cenário das escolas públicas daquela região, ao longo do período da pesquisa, a instituição completou seu segundo ano de funcionamento.

A cultura praticada naquela escola era a união das culturas escolares trazidas de outros espaços, tanto pelos agentes escolares como pelos alunos. Os valores, costumes, relações sociais, linguagens e símbolos que se apresentavam como locais eram tênues enquanto marcadores exclusivos daquele locus.

Ali existiam duas coordenadoras pedagógicas (CPs), uma foi participante ativa da pesquisa ao nos conceder entrevistas - CP1, e outra, que participou das construções, análises e ações desenvolvidas durante todo o estudo - CP2.

A professora de Educação Física (PEF) era jovem, com tenra experiência como docente em escola de Educação Básica há pouco mais de três anos. Sua dedicação era exclusiva àquela instituição.

A aluna, no período da pesquisa, era uma adolescente de 14 anos de idade, realizava um tratamento de um tumor no SNC e, em função da doença, perdeu progressivamente a visão.

Especialista em oncologia pediátrica do SNC, médica-técnica administrativa da Unifesp e profissional do Graacc, a médica de Helena também participou deste estudo nos concedendo entrevista e fornecendo uma série de esclarecimentos sobre a perda da visão e características do tumor de sua paciente.

Por fim, a pesquisadora participante (PP) principal deste estudo, que também é professora de $E F$, foi a campo e permaneceu na escola durante todo o segundo semestre do ano de 2013 , não somente observando, mas também atuando como professora quando posto em prática o projeto de intervenção composto pelas pesquisadoras.

O estudo foi realizado a partir das aulas de EF, uma ferramenta de socialização e desenvolvimento dos alunos que permite ao aluno viver experiências sensoriais, mesmo nas aulas que pretendem, como em outras disciplinas, controlar o corpo. É na aula de EF que há a possibilidade de expressividade corporal, das experiências de movimento e da significação dos mesmos (DARIDO, RANGEL 2008; GONÇALVES, 2012). 


\section{INSTRUMENTOS E PROCEDIMENTOS}

Sob o método da PA, aproximamo-nos da teoria habermasiana cujo foco é voltado à prática do diálogo em busca de consenso em prol da solução de problemas instalados em uma determinada sociedade. O desenvolvimento da metodologia se deu em diversas etapas que, ao longo da pesquisa, foram revisitadas devido à interdependência que havia entre elas, conforme demonstrado no Quadro 1 , a seguir:

Ocorreram dois encontros de apresentação da pesquisa à escola, no primeiro explicitamos às coordenadoras como seria realizado o projeto e qual problema desejávamos abordar. Neste momento solicitamos a autorização e a concomitante assinatura para a realização do estudo, no segundo, pudemos iniciar a ação em campo.

Quadro 1: Pesquisa ação, participantes, instrumentos e ação em campo por etapa.

\begin{tabular}{|c|c|c|}
\hline PARTICIPANTE & $\begin{array}{l}\text { INSTRUMENTO DE } \\
\text { COLETA DE DADOS }\end{array}$ & AÇÃO EM CAMPO \\
\hline $\begin{array}{l}\text { Pesquisadora } \\
\text { participante, Helena, } \\
\text { Professora de EF, } \\
\text { Coordenadora } \\
\text { pedagógica 1, médica } \\
\text { oncologista. }\end{array}$ & Entrevista 1 & $\begin{array}{l}\quad \text { Diagnóstico das } \\
\text { questões inicialmente } \\
\text { apresentadas por Helena, e, } \\
\text { também pelos demais } \\
\text { participantes envolvidos no } \\
\text { estudo. }\end{array}$ \\
\hline $\begin{array}{l}\text { Todas as } \\
\text { participantes } \\
\end{array}$ & $\begin{array}{cc}\bullet & \text { Diário de } \\
\text { Itinerância } 1 & \end{array}$ & $\begin{array}{l}\text { Observação das aulas } \\
\text { de EF ao longo de } 7 \text { semanas. }\end{array}$ \\
\hline Pesquisadoras e & $\begin{array}{cc}\bullet & \text { Entrevistas } 1 \\
\text { transcritas e } & \\
\bullet & \text { Diário de } \\
\text { itinerância 1 } & \end{array}$ & $\begin{array}{l}\text { Análise e reflexão dos } \\
\text { achados em campo }\end{array}$ \\
\hline Pesquisadoras & $\begin{array}{l}\bullet \quad \text { Projeto de } \\
\text { Educação Física, composto } \\
\text { por } 21 \text { aulas }\end{array}$ & $\begin{array}{l}\text { Apresentação de novas } \\
\text { iniciativas no espaço escolar }\end{array}$ \\
\hline Pesquisadoras & $\begin{array}{cc}\bullet \quad \text { Diário de } \\
\text { Itinerância } 2\end{array}$ & $\begin{array}{l}\text { Análise e reflexão dos } \\
\text { achados em campo a partir da } \\
\text { intervenção junto aos } \\
\text { participantes da pesquisa }\end{array}$ \\
\hline $\begin{array}{l}\text { Todas as } \\
\text { participantes }\end{array}$ & Entrevista 2 & $\begin{array}{l}\text { Análise das participantes } \\
\text { da pesquisa quanto à } \\
\text { intervenção realizada em } \\
\text { campo. }\end{array}$ \\
\hline Todas as & Diário de & Observação das aulas \\
\hline
\end{tabular}




\begin{tabular}{|c|c|c|}
\hline participantes & Itinerância 3 & de EF após intervenção. \\
\hline Pesquisadoras & $\begin{array}{cc}\bullet & \text { Entrevistas } 2 \\
\text { transcritas e } & \\
\bullet & \text { Diários de } \\
\text { itinerância } 2 \text { e } 3\end{array}$ & Análise e reflexão final. \\
\hline
\end{tabular}

A realização da investigação aconteceu desde a primeira aula do segundo semestre letivo de 2013 até o último dia de aula daquele ano, período em que aconteceu a formatura de ensino fundamental.

Tomando como referência os pressupostos até aqui desenvolvidos, este estudo foi constituído a partir do problema reclamado por Helena, do consentimento dos participantes envolvidos, da aprovação do projeto de pesquisa pelos comitês de ética da Unifesp e científico do Hospital do Graacc e, por fim, do início da fase diagnóstica do estudo, etapa caracterizada pela realização de entrevistas aos participantes já apresentados.

Com o término da primeira rodada de entrevistas, demos início ao processo de observação das aulas de EF entre 22 de julho e 4 de setembro de 2013, completando assim sete semanas de observação.

Tanto Barbier (2007), como Thiollent (1984) indicam que o caminho seguido pela PA requer um instrumento de registro que deve ser impregnado das impressões capturadas no contexto em que os envolvidos com a problemática estão inseridos de forma a documentar as experiências e o compreendido em campo. Adotado pela PP, nesse artigo será denominado diário de itinerância.

O conjunto das primeiras entrevistas, a relação com a comunidade escolar e as observações do campo permitiram a realização das primeiras análises que, por sua vez, geraram dados para o desenvolvimento de um plano de intervenção. Os participantes do plano de intervenção foram os alunos da turma de Helena, e, de forma indireta, as CPs e os demais professores da escola. A realização de tal plano foi a etapa da pesquisa que configurou nossa intervenção junto àquela comunidade escolar. E em 9 de setembro de 2013 foi ministrada a primeira das 21 aulas planejadas, iniciando, dessa forma, a etapa de intervenção, que caracterizava a pesquisadora professora de EF como PP do estudo.

Em função das alterações do calendário, a segunda entrevista com as participantes da pesquisa - Helena, PEF, CP1 - ocorreu enquanto a PP ainda finalizava o projeto de intervenção, porém, se fez necessário tal processo para que pudéssemos alcançar de conclusão da PA conforme planejamento, que consistia no retorno de Helena às aulas de EF regulares, sem a interferência direta da PP.

Todas as entrevistas foram realizadas com gravador digital para armazenagem dos dados. $\mathrm{O}$ conteúdo gravado foi transcrito para posterior análise e resultou em material fundamental para a produção dos dados.

Para facilitar a demonstração dos dados, foram definidas algumas categorias de análise e tais determinações sucederam-se após exaustivas leituras das transcrições das entrevistas. O que se percebeu nas seguidas leituras foram relações entre diferentes campos discursivos, tais como: Corpo, 
Câncer, Educação Física, Escola, Ressignificação, Lugar, Deficiência Visual, Relações Sociais, Formação Continuada, Individualização do paciente/aluno e Ações Multiprofissionais.

Por meio do agrupamento dos significados dessas diferentes discursividades, produzimos as três principais categorias de análise: Escola de Helena, Educação Física na Escola de Helena, Câncer e suas Implicações na Vida de Helena. Para tanto, foi necessário reunir as inúmeras informações advindas das entrevistas e do diário de itinerância que, alinhavadas ao referencial teórico adotado, abriram possibilidades de resposta para a pergunta central do estudo.

\section{RESULTADOS}

O fato dos alunos da turma de Helena não frequentarem ou participarem regularmente das aulas de EF não desvia nosso olhar da origem da pesquisa, Helena reclamar não ser entendida por aqueles que estavam na escola de origem, entretanto, nos obrigava a rever a forma de agir naquele contexto, visto que não haveria possibilidade de realizar a análise dos dados sob o eixo: o envolvimento do aluno em tratamento oncológico nas aulas de EF em sua escola regular, se não houvesse a realização contínua das aulas, com a participação de todos os alunos.

Diante do achados em campo, pudemos construir o plano de ação intitulado Projeto de Educação Física para o Segundo Semestre de 2013, que era a etapa da pesquisa que configurava nossa intervenção junto àquela comunidade escolar, foi entregue à PEF e às CPs daquela instituição na semana anterior a sua implementação, momento em que fomos convidadas a participar de uma reunião pedagógica para tratar de assuntos referentes à indisciplina da turma de Helena.

Antes mesmo de ministrar as 21 aulas do projeto mencionado, alunos, professores, funcionários, CPs e diretora enxergavam a PP como professora e não como pesquisadora. Este fenômeno facilitou a circulação da PP pelos mais variados espaços; aproximou-a dos colegas professores, que poderiam sentir-se intimidados pela presença da pesquisadora; fez com que as CPs dessem às pesquisadoras autonomia na construção das ações a serem realizadas junto à turma de Helena; promoveu a adesão do grupo à participação nas aulas de EF; alimentou de novos saberes e sabores a PEF; atingiu Helena, na condição de aluna e não de objeto de estudo. Além disso, propiciou nossa participação em reuniões pedagógicas da escola; fez a PP professora responsável pela turma quando a PEF faltava às aulas; fez com que funcionários nos requisitassem para solucionar questões com alunos de outras turmas.

Optamos, neste artigo, por apresentar excerto de fala das entrevistas que representem núcleos de significados de cada uma das três categorias já elencadas.

\section{AS AULAS DE EDUCAÇÃO FÍSICA NA ESCOLA DE HELENA}

Helena estava ausente em nosso primeiro dia de observação de campo, nesse momento, já notamos a falta de conexão entre a professora e os alunos. Dois movimentos justificam essa observação: no primeiro, a ausência de trocas sobre as vivências realizadas no período de férias, ou seja, o retorno à escola não apresentava nada de especial e, no segundo, o não cumprimento ao 
solicitado, já que foi indicado aos alunos copiarem o que a professora escrevia na lousa. A reverberação da cultura do movimento pelo movimento, tão disseminada ao longo dos anos na EF (DARIDO e RANGEL, 2008), pôde, naquele instante, impedir que os alunos percebessem a importância da proposta da professora em buscar fazer entender de forma teórica, aquilo que seria posto em prática em um segundo momento.

Araujo (2013) afirma que a aula que transmite um sentido aos sujeitos participantes dela, professor e alunos, faz com que estes se insiram verdadeiramente naquele dado tempo. Assim, o período destinado à aula é propício para trocas de saberes e cruzamento de culturas.

Durante a segunda aula do dia, não houve direção para as atividades a serem realizadas, todos foram levados para a área externa da escola. Lá, os alunos circulavam pela quadra e podia-se observar que usavam roupas do cotidiano, trajes de passeio e nenhum deles portava o uniforme apropriado para as aulas de EF fornecido pela SME.

O fato dos alunos não fazerem uso de vestimenta adequada para as práticas de atividades corporais fez-nos refletir sobre o significado da disciplina EF naquela escola. Alunos interessados em movimentar-se, mesmo não querendo fazer uso do uniforme, deveriam dispor de roupas apropriadas à prática. Em nosso entender, esses discentes usariam o mais oportuno para realizar ações corpóreas, não pela imposição da escola, mas pelo desejo de estarem ativos.

Ao reunir algumas falas da CP1 ao cenário observado na escola em estudo, sobretudo quanto aos alunos pouco participativos nas aulas de EF, percebemos conflito em algumas colocações.

Perante a fala da CP1:

Para esse segundo semestre a gente também está pensando em participar do campeonato dos jogos estudantis, então mostrar para eles que além da escola tem alguma coisa interessante.

em contraste com a constatação

A nossa quadra, como ainda não foi coberta, está ali na ação do sol e chuva. Ela está toda descascando mesmo, tem umas crateras, ela já está toda deformada.

Tornou-se difícil acreditar que aqueles alunos sairiam da escola para disputar qualquer tipo de campeonato, uma vez que os agentes escolares não enxergavam possibilidades de práticas naquele espaço. Nesse contexto contraditório, coordenação e docência manifestavam interesse em praticar algo que, caso ocorresse, poderia gerar frustrações e aumentar o descrédito da prática, pois se era desejado que os alunos disputassem campeonatos externos, sem treino, a chance de voltarem derrotados para casa era eminente. Constatamos que o espaço da EF não era próprio para treinamento esportivo, mas era para a prática inclusiva da cultura corporal de movimento.

Nesse sentido, Habermas (1990) aponta a proposta do diálogo entre as partes envolvidas, ou seja, ele indica que na condição de fala pode-se gerar o respeito mútuo e o consenso de uma comunidade diante dos conflitos de sua cultura. Portanto, antes de se propor aos alunos que participassem de campeonatos fora da escola seria necessário incentivá-los e, fundamentalmente, saber se eles desejavam fazê-lo, pois a prática pela prática não geraria frutos. 
Não houve fala quanto à participação de Helena nas aulas.

\section{CÂNCER E SUAS IMPLICAÇÕES NA VIDA DE HELENA}

Em observação de campo podemos afirmar que é certo que Helena preferia não divulgar o fato de ser doente, mas também era conhecido que sua professora tinha ciência de que a doença existia e interferia na vida da aluna.

Foram diversas conversas realizadas com a PEF e, na segunda entrevista gravada, obtivemos os seguintes relatos.

\section{PP: Faz alguma diferença a Helena ter câncer?}

PEF: Para mim não, para mim não faz. Eu trato a Helena como qualquer outro aluno. E por incrivel que pareça acho que para ela também não. Ela se situa em pé de igualde com os outros, principalmente na questão de conhecimento, a produção teórica dela, a parte de desenho dela, excelente. Os desenhos que a Helena faz, as charges... Ela gosta de fazer charge, é excelente. O que pesa nisso tudo, que eu já falei isso lá no início para você, eu acho que talvez ela não saiba da gravidade. Noção da gravidade e do problema dela, na minha opinião eu acho gravíssimo. A mãe, de alguma forma... ou ela também não tem esse conhecimento. Eu acho que a mãe não tem também a visão da seriedade que é, e das vezes que ela se isenta de algo porque ela [Helena] não vai conseguir.

Quando ao ser questionada se fazia alguma diferença Helena ter um câncer, a PEF nos forneceu uma resposta que pode ser entendida por duas ramificações. Ao afirmar que aquela é uma aluna como qualquer outra, concordamos com a docente: Helena se iguala aos demais no sentido de frequentar a escola para partilhar da mesma formação que seus colegas, entretanto, os caminhos para que se atinjam os objetivos comuns a Helena e sua turma não necessariamente serão os mesmos que os dos demais alunos de outras turmas, portanto, nesse sentido, ela deixa de ser igual aos demais.

\section{$P P$ - Não faz diferença ela ter câncer, mas faz diferença ela não enxergar?}

PEF - Faz diferença ela não enxergar. Não só porque não dá para adequar a aula totalmente para ela, porque se você adequar a aula só para ela, de alguma forma os outros também deixam de fazer algumas coisas que são necessárias para eles.

Helena diz que não é deficiente visual. Ela já desenvolveu de alguma forma um escudo. E que vai protegendo ela de todas essas coisas que ela deve sentir. Medo, medo não só da intolerância, da ignorância, mas o medo de não ver mais nada, porque ela sabe que ela tem um resquício ali, mas e na hora que ela não ver mais nada?

Parecia faltar diálogo na relação entre elas, visto que a aluna se perdia entre a deficiência sensorial e seu estado de saúde e não havia essa leitura pela docente. Para que esse entendimento ocorresse por ambas as partes, seria necessário que houvesse troca de informações e saberes, fosse 
via diálogo entre professora e aluna, fosse por vias institucionais, já que a troca de conhecimentos acerca das especialidades da aluna era indispensável para que houvesse melhor esclarecimento das posturas tanto por parte da aluna como da professora. Sendo o encadeamento das questões biológicas de Helena ignorado, haverá reflexo dessa ocultação de implicações em outros fatores de sua vida. Quando a professora não compreendeu que as práticas corporais daquela discente apresentavam restrições e necessitavam de atenção e cuidados além dos usuais, ela confundiu o olhar sobre a aluna e terminou por pensar que, em função do medo ou pela castração da mãe, não era autônoma ou que se acomodava conforme a conveniência do momento.

Justamente para tratar das questões envoltas à doença, ao tumor, ao câncer, foi realizada uma longa entrevista com a médica de Helena, que nos auxiliou na composição das aulas que foram ministradas pela PP do estudo e, também, na compreensão da forma como a instituição de saúde lida com seus pacientes diante da existência do tumor.

PP - Quando a escola faz contato para querer saber da criança é sempre via EMAE ou existe caso da escola querer vir atrás dos médicos?

M - Faço um relatório para escola situando, como que está a criança, como ela está tratando e o que ela pode fazer. Indicando se ela pode ir para a escola, quando não puder tem que ter assistência, porque muitas vezes está vomitando, porque isso, porque aquilo outro. Eu me ponho à disposição. No momento a gente faz relatórios médicos para a escola, aqui por exemplo, tudo é através da EMAE. Nós temos que enxergar o que eles podem fazer e continuar reabilitando e reintegrá-los na sociedade. Então isso é a nossa função. É tratar e depois do tratamento não é para abandonar a criança. É um grupo que dá apoio. Toda a equipe multiprofissional tem que dar apoio e ser disponível. Não é falar assim: "Já que tratou, vai embora!"

O trabalho docente não é fácil e o do médico também não, enquanto na escola os agentes deparam-se com um elevado número de alunos problemáticos, os médicos convivem com crianças e famílias que percebem a possibilidade de fim da vida mais próxima do que a maioria das crianças da escola. A questão é a maneira pela qual cada instituição lida com as adversidades instaladas em seu público. Para identificar soluções é necessário conhecer-se os problemas, mas o foco deve ser voltado à resolução das dificuldades e não ao exclusivo apontamento delas.

Barbier (2007) afirma que se temos a intenção de situar uma pessoa em um local, necessariamente, temos de reconhecer as complexidades que a envolvem, levando-se em conta as suas capacidades criadoras e respeitando a sua liberdade. Pelo que vivenciamos no ambiente escolar, percebemos que alguns professores enxergavam a família, a coordenação pedagógica, as diretrizes curriculares, as ações dos alunos, enfim, tudo ao redor como empecilho de ações e não como possibilidades delas.

No hospital, as famílias são estimuladas e envolvidas no processo de recuperação dos enfermos e, segundo a médica, ao perceberem a evolução positiva de seu ente querido, as famílias 
colaboram ainda mais. Desenvolve-se, portanto, uma relação de parceria entre família e hospital na tentativa de amenizar o impacto da doença e do tratamento. Ela ainda fala do comprometimento que assume junto aos seus pacientes e familiares e explica que não é fácil desenvolver esse trabalho, mas é possível.

Quando questionamos Helena sobre sua enfermidade e a relação com a escola, obtivemos as seguintes respostas.

\section{PP - Os professores já pararam para te perguntar porque você falta muita aula?}

Helena - Já. Eu falava que era por causa do tratamento. Quando eu termino [o tratamento], tem vezes que eu não fico bem mesmo, coisas simples, tipo resfriado, essas coisas, eu sempre dou minha justificativa. Já tiveram a cara de pau de falar que eu estava com preguiça de vir.

\section{PP - Aqui nessa escola?}

Helena - Nessa sim. Mas aí eu reponho sempre que eu falto, eu reponho a lição, corro atrás.

A aluna cronicamente enferma não era percebida pelos professores como alguém que demandava atenção diferenciada para ser tratada de maneira diferente de uma aluna comum, no entanto, Helena manifestava diferença e sensação de não pertencimento em relação à rotina escolar.

Fernandes (2013) indica que, por meio das relações reflexivas, os conflitos, os afetos, os encontros e os desencontros organizam novas possibilidades de se trabalhar o conhecimento e, como um processo de construção coletiva e contínua, pode-se dar lugar à prática social crítica e autônoma que tenha significação verdadeira para todos os envolvidos.

\section{A ESCOLA DE HELENA}

Foi na terceira aula observada que tivemos a oportunidade de realizar a primeira entrevista com Helena, quando em seu primeiro dia na escola depois das férias revelou-nos o seu histórico escolar e também as percepções que tinha sobre a escola que frequentava naquele momento.

Quando Helena nos apresentou seu histórico relacionado à escolarização, percebemos a presença da família no início da jornada estudantil. Em diversos momentos ela fez comparação da avó com o seguimento educacional próprio para o estágio de desenvolvimento infantil, a creche, e revelou a confusão de papéis estabelecidos naquelas vidas. Quando estava na alfabetização, primeiro contato com a escola, precisou interromper a rotina escolar para colocação de uma válvula na cabeça.

\section{PP - E como foi voltar para a escola após um período afastada para o tratamento do tumor?}

Helena - Foi difícil voltar para a escola porque teve todo o preconceito dos alunos, o cabelo caiu, aí teve tudo isso, até [dito de maneira prolongada, indicando muito tempo] a sétima série.

PP - Mas você tinha alguns professores que te ajudavam? 
Helena - Só na terceira série que eu tinha a profa. Marcia [da escola anterior à atual] que me ajudava.

Toda a jornada estudantil de Helena esteve vinculada à neoplasia e ela perdeu a oportunidade de construir a referência de ser uma aluna como a maioria de seus colegas, desprovidos de patologias crônicas. Com a apresentação de documentos ligados ao IOP/GRAACC/Unifesp houve esclarecimento das particularidades de Helena advindas da neoplasia instalada em seu corpo, contudo, foram necessários alguns anos de experiência escolar para que aquela aluna se percebesse plenamente compreendida por uma professora de classe; apenas na terceira série do Ensino Fundamental aquela aluna percebeu ser de fato entendida e atendida por sua professora.

PP - Você conhece o pessoal da coordenação da sua escola atual?
Helena - Pelo nome não, mas conheço de falar [as coordenadoras].
PP - É importante essas pessoas se aproximarem de você?
Helena - Sim.
PP - Na escola antiga você tinha essa aproximação?
Helena - Ahhhhh, não muito.
PP - E você acha que o fato de você se aproximar dessas pessoas pode te
ajudar no desenvolvimento dentro da escola?
Helena - Pode.
PP - Como é que você avalia seu desempenho escolar?
Helena - Bem. Em inglês eu estou bem, português eu estou ruim, em EF eu
estou um pouquinho mais ou menos.

(os colchetes são de autoria das pesquisadoras)

Helena tinha na escola um recurso para se aproximar da vida comum, da vida de uma adolescente que não tem problemas de saúde.

As CPs e a PEF tinham conhecimento da existência do tumor e das implicações geradas pelo fato. Existia tolerância quanto às faltas, mas não percebemos a realização de ações pedagógicas que preenchessem o vazio constituído pela baixa frequência escolar, assim como pela perda gradual da visão. É destaque a importância do reconhecimento dos agentes escolares sobre as implicações que a doença crônica impunha à vida da estudante. A aluna manifestou que o conhecimento da existência da doença auxiliava seu desenvolvimento e reconhecia que o interesse do professor pelo seu caso era relevante, possibilitando melhor desenvolvimento de sua atividade estudantil.

Ao conversar com CP1 sobre a pesquisa desenvolvida junto àquela comunidade, obtivemos as respostas que são apresentadas a seguir.

$P P$ - Esse tempo que passamos na escola ajudou, atrapalhou ou não influenciou em nada? CP - Ajudou e colaborou muito. Porque, assim, acho que nós estávamos precisando de 
outras visões. Como a $8^{a}$ série é uma turma muito complicada, a gente estava testando possibilidades. Porque a gente viu que só trabalhar o conteúdo não ia funcionar com eles. Então a gente precisava mesmo de alguém com outro olhar para propor uma atividade diferenciada. Até para gente perceber que algo daria certo ali. Como era uma turma muito complicada, então, cria-se uma certa barreira. Quando você que está dentro da escola começa a propor, você já tem aquela postura do "não vai dar certo". E quando vem alguém de fora e propõe alguma coisa que dá certo, acho que traz alguma coisa assim "não, a gente vai conseguir, a gente também pode tentar alguma coisa, propor para eles coisas diferentes, que vai dar certo".

\section{$P P$ - O que que você acha que deu certo?}

$C P$ - Acho que esse envolvimento com os alunos. É você propor no início, pensar na Helena, só que de repente a sala também pode começar a conversar entre eles, criar algum vínculo, algum respeito, para tentar chegar. Nós não conseguimos chegar ao conteúdo que nós tínhamos que trabalhar com a 8 a série, porém, nós conseguimos desenvolver algumas atividades para que eles se respeitassem mais, para eles se verem como alunos. Porque essa identidade não foi construída, essa identidade para eles foi algo quebrado, que cada um trouxe de outras escolas e ao chegaram aqui eles não conseguiram construir e, quando você não tem essa identidade no grupo, é muito difícil.

Os agentes escolares perceberem que havia como agir de forma diferente do que vinham praticando e assumirem que estavam descrentes de possibilidades de mudanças internas foi um grande passo para que as soluções de seus problemas passassem a ser geradas por eles próprios.

Fernandes (2013) afirma ser necessário entender a importância da identidade do grupo formada pelo diálogo, com a finalidade de fortalecer os vínculos, tecendo, dessa maneira, as teias que transitam entre o afeto, a ética, o rigor epistemológico e a responsabilidade. Por esse caminho não há determinação exata de fórmulas, momentos ou locais da ação, pois tudo isso é consequência da construção estabelecida anteriormente e não o determinante dessa construção.

Nesse sentido torna-se fundamental que os agentes escolares tenham conhecimento das particularidades que marcam seus alunos e dialoguem sobre essas marcas, não com intenção de evidenciá-las, mas como possibilidade de não as ignorar, afinal, em sua trajetória, tais marcas são partes constituintes e não podem ser abandonadas.

\section{ALGUMAS CONSIDERAÇÕES}

Voltado ao fenômeno que ocorre em um cenário restrito e localizado - o do aluno cronicamente enfermo não se sentir pertencente por completo às instituições que o auxiliam em seu desenvolvimento (hospital e escola) - como problema, este estudo tem intenção de inteirar pesquisadores e profissionais da área da educação e também da saúde a fim de manifestarem interesse pelo atendimento integral de crianças e adolescentes que permanecem doentes por longos períodos. 
O olhar depositado neste estudo se deu pela EF vista pela vertente da globalidade dos sujeitos, que mesmo cronicamente enfermos são passíveis de ações e expressões. Entretanto, as considerações expostas mostram suscetibilidade de ação em conjunto com outras disciplinas que envolvam educação e saúde de alunos cronicamente ou gravemente adoecidos. A possibilidade de crianças e adolescentes serem acometidos por uma doença grave é um fato. No entanto, há elementos e fenômenos em suas vidas que, quando conduzidos de modo correto, podem amenizar o impacto da enfermidade.

Assim, consideramos que a ressignificação do lugar ocupado pelo aluno paciente oncológico de baixa visão se dá pela: formação autônoma do aluno; pela construção de um ambiente em que todos aprendam; pela compreensão da enfermidade e de suas implicações na construção do currículo escolar, pelo espaço de complementaridade entre a cultura escolar e as possibilidades e necessidades do aluno gravemente enfermo; inclusão de aspectos formativos profissionais em locais que envolvam a resolução de problemas do cotidiano escolar, por tomar para si as individualidades na presença do todo por parte dos envolvidos com o processo de escolarização da Educação Básica; pela aprendizagem da docência em paralelo a modos de reflexão sobre as questões do cotidiano; criação de artefatos formativos que possibilitem trocas de papéis sem a perda da especificidade de cada um.

Estivemos a apontar necessidades e possibilidades dentro de um contexto restrito e, ao final desta experiência, como depois de uma longa viagem, ao retornar, chegamos à escola, aos alunos, às famílias, aos professores e à comunidade hospitalar alterados pela reflexão teórico-prática, pela convivência ética e humanizada entre todos os envolvidos. Resta agora empreendermos outras jornadas. 


\section{REFERÊNCIAS}

ARAUJO, José Carlos Souza. Disposição da aula: os sujeitos entre a tecnia e a polis. In: VEIGA, IIma passos Alencastro (org.). Aula: Gênese, dimensões, princípios e práticas. 2a ed. Campinas, SP: Papirus, 2013. p. 45-72.

2. BARBIER, René. A pesquisa-ação. Tradução de Lucie Didio. Brasília, DF: Liber Livro Editora, 2007. 159 p. (Série Pesquisa).

3. BRASIL. Ministério da Educação e Cultura. Lei de Diretrizes e Bases da Educação Nacional n. 9394/1996. Brasília: Imprensa Oficial,1996.

4. Ministério da Educação. RESOLUÇÃO CNE/CEB n 02, 2001. Institui Diretrizes Nacionais para a Educação Especial na Educação Básica. Brasília: Imprensa Oficial, 2001.

5. COVIC, Amália Neide; OLIVEIRA, Fabiana Ap. De Melo. O aluno gravemente enfermo. São Paulo, SP: Cortez, 2011. 128 p. (Coleção Educação \& Saúde).

6. DARIDO, Suraya Cristina; RANGEL, Irene C. Andrade. Educação Física na Escola: implicações para a prática pedagógica. Rio de Janeiro, RJ: Guanabara Koogan, 2008. 293 p. (Educação Física no Ensino Superior).

7. FERNANDES, Cleoni Maria Barboza. À procura da senha da vida- de-senha a aula dialógica? In: VEIGA, IIma Passos (org.) et al. Aula: Gênese, dimensões, princípios e práticas. 2a ed. [3. Reimp] Campinas, SP: Papirus, 2013. p. 145-165.

8. GEERTZ, Clifford. A interpretação das culturas. 1. ed. [Reimp.]. Rio de Janeiro, RJ: LTC, 2012. 216 p.

9. GONÇALVES, Maria Augusta Salin. Sentir, pensar, agir: corporeidade e educação. 15a. Ed. Campinas. São Paulo: Papirus, 2012. p.13-37. (Coleção: Corpo e Motricidade).

10. HABERMAS, Jurgüen. Pensamento pós-metafísico. Rio de Janeiro, RJ: Tempo Brasileiro, 1990. $271 \mathrm{p}$.

11. HABERMAS, Jurgüen. Teoría de la acción comunicativa: complementos y estudios previos. Trad. Manuel Jiménez Redondo. Madrid: Catedra, 2001. 507 p.

12. KREMER, Leontien C.M.; et al. A worldwide collaboration to harmonize guidelines for the long-term follow-up of childhood and young adult cancer survivors: A report from the international late effects 
of Childhood Cancer Guideline Harmonization Group. Pediatr. Blood Cancer (2013), 60: 543-549. DOI:10.1002/pbc.24445. Acesso em 14 nov. 2013.

13. PETRILLI, Antônio Sérgio et al. Cuidados Intensivos no Paciente 6Oncológico Pediátrico. In: CARVALHO, Werther Brunow; CARDOSO, Eduardo da Silva. Terapêutica e prática pediátrica. São Paulo, SP: Atheneus, 2000, p. 1251-1334.

14. PEMBERGER, Sigrid; JAGSH, Reinhold; FELDER-PUIG, Eva Frey Rosemarie; GADNER, Helmut; KRYSPIN- EXNER, Ilse; TOPF, Reinhard. Quality of life in long-term childhood cancer survivors and the relation of late effects and subjective well-being. Support Care Cancer (2005) 13: p.49-56. DOI 10.1007/s00520-004-0724-0. Acesso em 14 nov. 2012.

15. THIOLLENT, Michel Jean-Marie. Aspectos qualitativos da metodologia de pesquisa com objetivos de descrição, avaliação e reconstrução. Cadernos de Pesquisa, (49), maio 1984. p. 45-50.

\section{Isabela Lemos de Lima Cascão}

Doutoranda no Programa de Pós Graduação Educação e Saúde na Infância e na Adolescência Unifesp. Docente no curso de Educação Física na Universidade de Mogi das Cruzes - UMC.

\section{Amália Neide Covic}

Doutora em Educação-Currículo - PUC/SP. Docente Colaboradora: Programa de Pós Graduação Educação e Saúde na Infância e na Adolescência - Unifesp. Coordenadora e Docente no de Especialização Multiprofissional em oncologia pediátrica na área hospitalar e ambulatorial - Unifesp. Coordenadora da Escola Móvel/Aluno Específico, serviço de atendimento escolar do Instituto de Oncologia Pediátrica - Grupo de Apoio ao Adolescente e à Criança com Cancer (IOPGRAACC/Unifesp. Pesquisadora do IOP-GRAACC/Unifesp.

\section{Como citar este documento}

CASCÃO, Isabela Lemos de Lima; COVIC, Amália Neide. Educação Física Escolar: tenho câncer e baixa visão, posso participar?. Reflexão e Ação, Santa Cruz do Sul, v. 28, n. 1, jan. 2020. ISSN 19829949. Disponível em: <https://online.unisc.br/seer/index.php/reflex/article/view/12692>. Acesso em:__ doi:https://doi.org/10.17058/rea.v28i1.12692. 